\title{
Impure Foods: Entanglements of Soil, Food, and Human Health in Bangladesh
}

THIS BRIEF EXPLORES A LOCAL ontology of health and purity of food in Bangladesh to discuss the effects of agricultural "modernization" and how it is transforming people's relationship to the land and ultimately their sense of self and well-being. It contributes to existing debates on the moral dimensions of what constitutes good food by looking at the tension between globally good foods such as high-yielding varieties of rice that aim to combat hunger and local (desi) rice, grown more slowly and without (imported, nonquality assured) agrochemicals, which is perceived as purer, tastier, and more nutritious.

During my ethnographic fieldwork in Bangladesh, my interlocutors described how food was grown without synthetic chemicals in the past; it was filled with both shakti (strength, power) and pushti (nutrition). In contrast, food today-grown with synthetic chemicals - is bhejal (impure, adulterated) and lacks strength and nutrition. Bhejal foods, they argued, make current generations weak and ill, while the use of agrochemicals degrades the soil for future cultivation. The current landscape of food production and development aid has moved away from a local ontology of health, where the self is entangled with the soil, and is instead reproducing a socially unjust, toxic, and unsustainable food system. Instead of producing good food, the current agricultural system in Bangladesh is producing impure, harmful foods, similar to the large-scale production of soft wheat in Morocco (See Graf this issue). This illustrates the contentiousness of a universally good food of high-yielding varieties - promoted globally as a means to combat Third World poverty and hunger (See also Tak this issue) - that is seen as antithetical to food locally conceived as "good."

The Bengali proverb "rice and fish makes a Bengali" highlights the importance of food for identity. This, in turn, is tied to ideas of how humans are connected not only to the food they eat, but the soil from which the food originates. My elderly interlocutor Fupu described that since the introduction of high-yielding IRRI (International Rice Research Institute) rice and its dependence on synthetic nitrogen, there is less shakti in the soil and thus less shakti in the food and, ultimately, less shakti in humans. Shakti means power and, in Hinduism, shakti is the primordial cosmic energy that gives birth to the universe: Shakti is the mother goddess (Lowitz and Datta 2004: 111). Farmers explained that synthetic fertilizers lack shakti and thereby "suck the earth dry," making it inhospitable to earthworms essential for shakti. While synthetic nitrogen is only one of many nutrients, organic matter fertilizers like manure and compost consist of an assemblage of the macro- and micronutrients a plant requires, filled with earthworms and all other microorganisms essential for soil fertility. Both shakti and micronutrients are invisible to the eye. The soil itself is a universe of micronutrients, microorganisms, and earthworms.

Tsing (2015) suggests that different species influence each other in open-ended assemblages. Both Ingold (2008) and Tsing (2015) use fungi as a basis to illustrate how organisms and nature are entangled, and the multitude of ways in which they interact. We still do not fully understand the assemblages of species in the soil, and to what extent the concerns regarding the loss of micronutrients, microorganisms, and shakti may potentially be connected. Due to the lack of shakti in food, my interlocutors argued, younger generations are weaker and more prone to illness. High-yielding rice may produce large quantities, but its lack of strength reduces the goodness of rice.

The lack of shakti is further exacerbated by the lack of food safety enforcement in Bangladesh. The (over)use of synthetic fertilizer makes IRRI rice "sweet" and attractive 


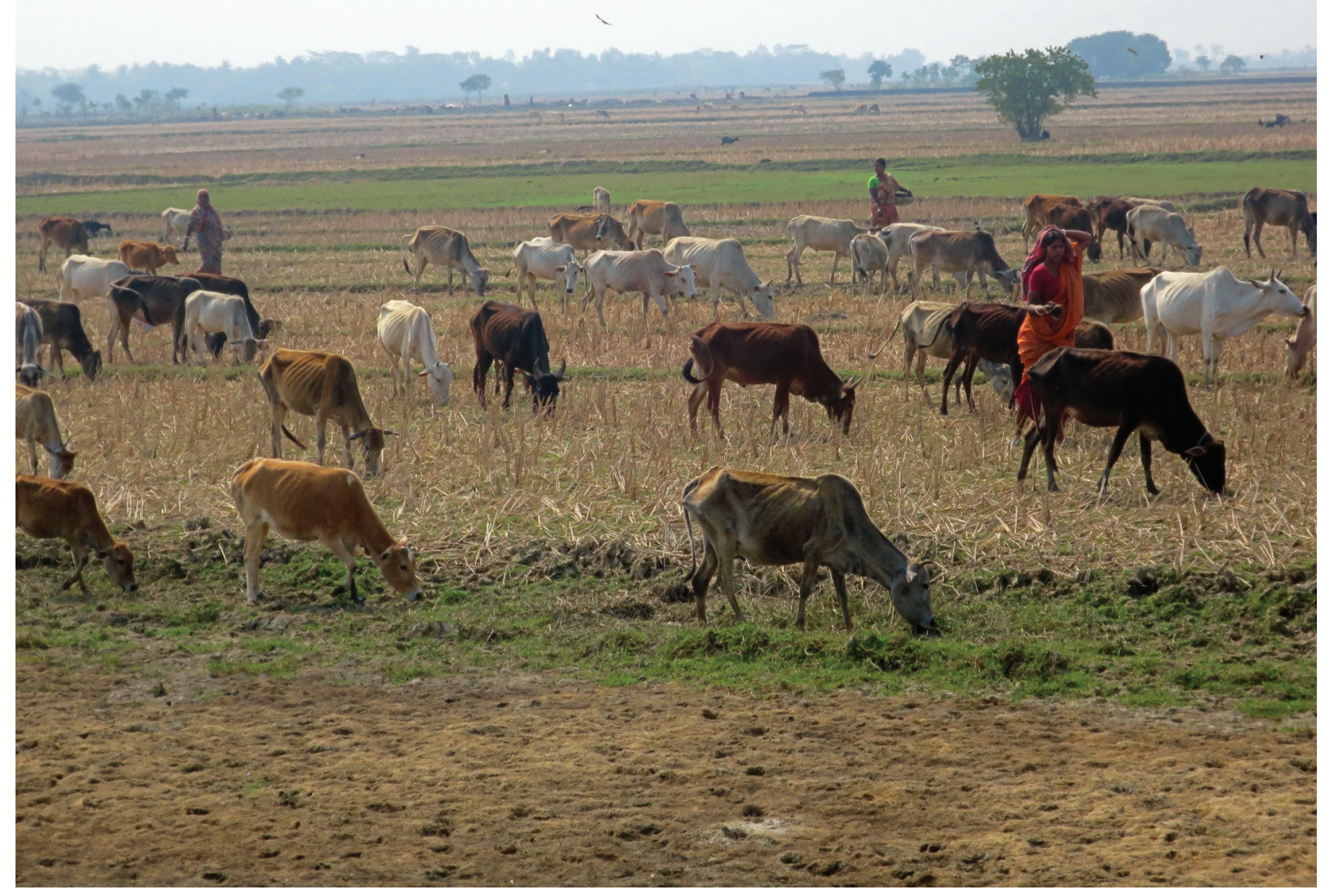

FIGURE 1: Bangladeshi cows and cow dung collection.

PHOTOGRAPH BY CAMELIA DEWAN (C) 2015

to pests. In contrast to "bitter" local varieties, IRRI rice cannot be cultivated without pesticides. Many of the pesticides used by Bangladeshi farmers are banned by the WHO and described as "obsolete," such as Endrin and organochlorines like DDT. Banned pesticides and contaminated fertilizers are easily smuggled into Bangladesh. Fupu pointed out that the environment has become toxic and that all food today is bhejal. Bhejal food denotes an impurity borne from adding external substances that diminish the quality of the food itself, whether it be too much synthetic urea, poisonous pesticides, formalin (to prevent rot), ripening chemicals, fillers (brick powder in spices, motor oil in cooking oil), or unregulated colorings. My interlocutors explained that bhejal foods contribute to kidney, liver, and stomach problems; stroke, cancer, and heart problems were also on the rise.
With the intensification of commercial agriculture and the commodification of food, food shifted from being embedded in a social context to an anonymous commodity to be sold in a depersonalized market by nameless sellers. The local understanding of how soil, food, and humans are entangled - captured in the transmission of shakti-has been lost. As profits increased, shakti necessary for human health decreased and bhejal foods came to dominate the market. The concept of bhejal in the Bangladeshi context points to the ways in which things are allowed to become adulterated, whether through an overuse of fertilizer and a lack of shakti, the use of banned and toxic pesticides, or the adulteration of food - all in order to increase profit. As both rice and fish have become bhejal through large-scale, globally oriented production, Bengalis themselves have become bhejal: both morally and physically corrupted, with an embodied weakness ridden with ill health. @ 


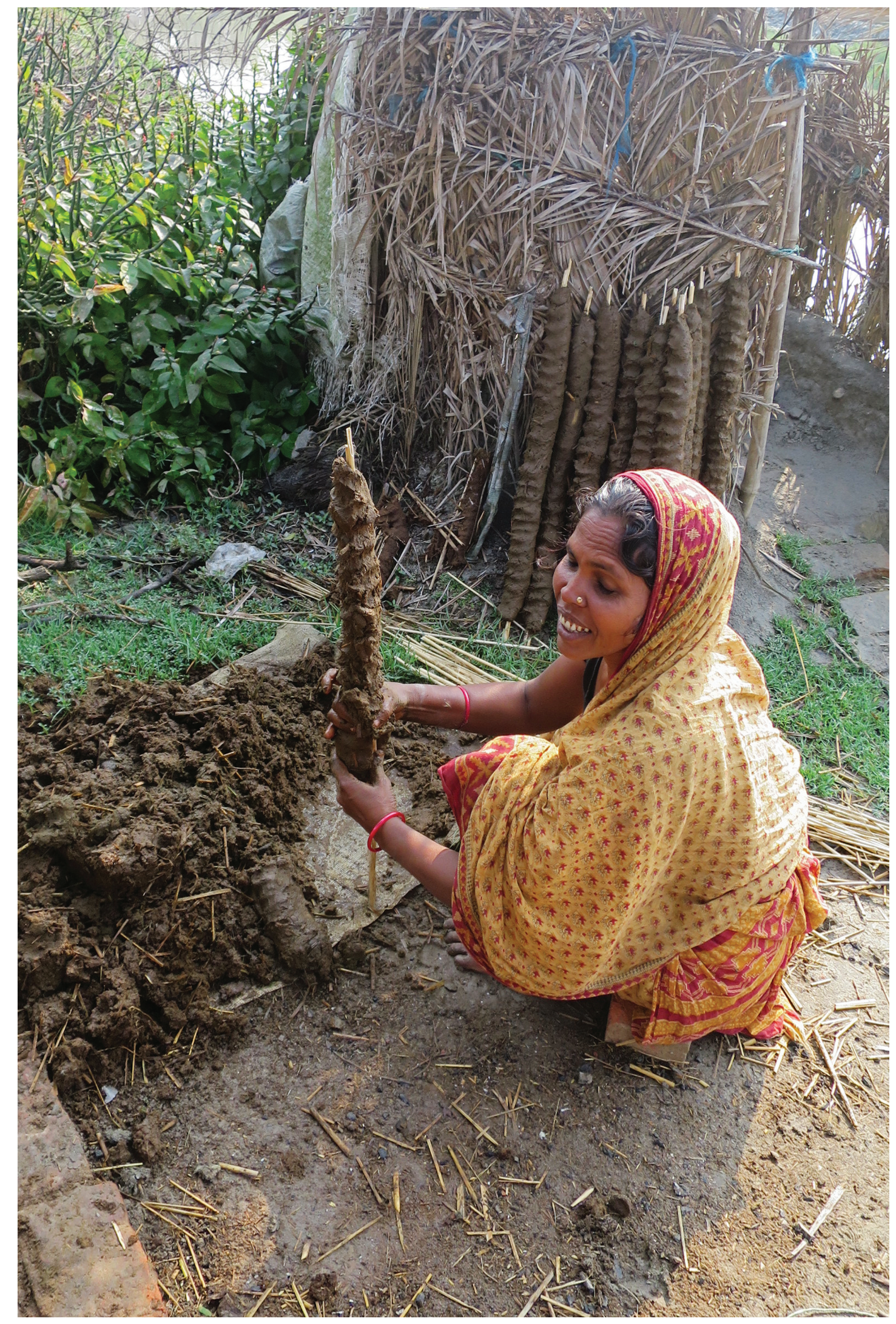

figure 2: Preparing cow dung, Bangladesh. 
REFERENCES

Ingold, Tim. 2008. "Bindings against Boundaries: Entanglements of Life in an Open World." Environment and Planning A 40(8): 1796-810.
Lowitz, Leza, and Reema Datta. 2004. Sacred Sanskrit Words: For Yoga, Chant, and Meditation. Albany, CA: Stone Bridge Press. Tsing, Anna Lowenhaupt. 2015. The Mushroom at the End of the World: On the Possibility of Life in Capitalist Ruins. Princeton, NJ: Princeton University Press. 